\title{
Educação Médica e Integralidade: o Real Desafio para a Profissão Médica
}

\section{Medical Education and Integrality: the Real Challenge for Medical Profession}

\author{
George Dantas de Azevedo ${ }^{(1)}$, Maria José Pereira Vilar ${ }^{(2)}$
}

A insuficiência e inadequação do conteúdo disciplinar das escolas médicas ao formar médicos despreparados para abordagem da clientela em ambiente extrahospitalar vêm sendo há muito criticada, na medida em que se priorizam a formação especializada e científica. A prática focada em diferentes espaços, tais como o ambulatório, a família, o trabalho, a escola, por trabalhar com um referencial de objeto que não somente a medicina hospitalar, mas também o social, não tem encontrado correspondência adequada na abordagem das escolas médicas ${ }^{(1)}$.

A fragmentação instituída entre os diversos aspectos que compõem a formação integral do médico (trabalho intelectual, estudo, treinamento em Serviços, ética e humanismo) atingiu uma dimensão tal a ponto de motivar a discussão sobre a necessidade da adoção de estratégias que, efetivamente, promovam maior coerência entre o que se ensina e o que é prevalente e relevante no dia-a-dia da assistência às necessidades e demandas das pessoas e das comunidades.

Os problemas com os quais a medicina se depara nos dias atuais estão intrinsecamente relacionados com o processo de formação de estudantes, residentes e docentes. Esse aspecto vem sendo reconhecido em todas as partes do mundo, deflagrando-se uma verdadeira reforma universal no campo da educação médica. Como indicador fidedigno da relevância do tema na atualidade, destacamos a recente publicação de uma edição inteiramente dedicada a artigos sobre educação médica no JAMA (The Journal of the American Medical Association; volume 296, número 9, setembro de 2006), um dos mais importantes periódicos científicos da medicina em todo o mundo. Fatos dessa natureza vêm reafirmar a tendência mundial de mudança nas diretrizes de formação de um novo profissional médico, com habilidades para atuar nos mais diferentes aspectos da vida e da saúde das populações.

A reformulação do ensino médico contempla não apenas os conteúdos formativos, mas, sobretudo, pressupõe uma reforma nos aspectos metodológicos, incluindo maior enfoque ao aprendizado com base em problemas clínicos, interação com o paciente e a comunidade desde o início do curso, predominância de atividades práticas sobre as teóricas, trabalho em equipe e maior aproximação com as ciências humanas e sociais. Adicionalmente, os princípios que regem essa reformulação na busca da integralidade na formação médica estabelecem que preceitos de ética, humanismo e responsabilidade social devem perpassar de forma transversal todo o processo de treinamento dos estudantes de medicina, capacitando-os para o exercício da profissão de forma mais competente $e$ adequada às necessidades da sociedade ${ }^{(2-7)}$.

Nesse sentido, é necessário que a educação médica se estabeleça definitivamente em novos cenários, em que as práticas assistenciais estejam ocorrendo e não somente no hospital. A integração entre ensino, pesquisa e serviço deve ser ampliada, abrangendo os postos de saúde, os programas de assistência domiciliar, os centros de atenção psicossocial, as escolas e outros locais. Estudantes de medicina e médicos residentes precisam compor com os profissionais de todas as categorias que trabalham na saúde, compreender as dificuldades e as possibilidades das práticas conjugadas e viver o cotidiano do Sistema Único de Saúde (SUS $)^{(8)}$. A despeito do reconhecimento global quanto à pertinência dessa ampliação de cenários de ensino-aprendizagem, o que se observa na prática é que as escolas médicas, parti- 
cularmente aquelas mais tradicionais e de financiamento público, vêm enfrentando extrema dificuldade para implementação dessas novas diretrizes. Existe grande resistência por parte de estudantes e parcela dos docentes no que diz respeito à migração para cenários externos ao ambiente hospitalar. Tocando o cerne do sistema de valores da profissão médica, as propostas que visam ao deslocamento do eixo hospital/atenção individual/especialização geram conflitos e resistências à sua efetivação, à medida que atingem o status profissional e a representação perante si e a sociedade. Assim sendo, tais propostas são entendidas, sob o ponto de vista do reconhecimento social, do prestígio e do valor profissional, como menos prestigiosas, ameaçando, assim, a autonomia profissional e gerando conflitos e inseguranças ${ }^{(9)}$.

São muitos os espaços coletivos, formais e informais que buscam reorientar a formação médica no Brasil, inclusive as políticas públicas do governo federal. Cabe destacar primeiramente o Promed (Programa de Incentivo a Mudanças Curriculares nos Cursos de Medicina) e, mais recentemente, o ProSaúde, uma ação interministerial (Ministério da Saúde/Ministério do Educação - MS/MEC) de apoio às escolas médicas para a adequação do ensino e à produção do conhecimento e dos serviços no país, na lógica da reafirmação das orientações contidas nas Diretrizes Curriculares dos Cursos Médicos. Essa última política, em fase atual de implementação, é dirigida não somente ao curso de medicina, mas também aos cursos de enfermagem e odontologia, já avançando no caminho da valorização do trabalho em equipe na saúde. Particularmente em relação à medicina, a política apóia cerca de vinte universidades brasileiras de diferentes regiões, que tiveram seus projetos de mudanças selecionados para participar.

Dentre os diversos fóruns nos quais essas outras questões relacionadas ao ensino médico são discutidas com todos os atores envolvidos, destaca-se o papel fundamental do Congresso Brasileiro de Educação Médica, promovido anualmente pela Associação Brasileira de Educação Médica (ABEM), que, nos últimos anos, vem priorizando temas da maior relevância, como avaliação das escolas médicas, atenção básica, internato, residência médica e integração ensinoserviço. No que concerne ao último tópico, as discussões têm se intensificado desde o congresso de 2005, realizado em Natal (RN), cuja temática central foi "Educação Médica - Compromisso Histórico com o SUS", culminando com a última edição realizada recentemente em Gramado (RS), que teve como eixo central das discussões o tema "Interação Escola Médica, Serviço de Saúde e Sociedade". Este, mais uma vez, reafirmou a necessidade da integração dos diversos atores envolvidos com a formação do médico brasileiro, ainda mais num momento extremamente fértil em que vivenciamos mudanças curriculares em várias escolas e diversos mecanismos institucionais de fomento e promoção dessas mudanças ${ }^{(10)}$.

O 44ํㅡㄹ Congresso de Educação Médica foi realizado de 24 a 27 de outubro do presente ano e, a despeito do clima gelado de Gramado, as diversas atividades transcorreram em clima de intenso calor científico e de interação entre estudantes, professores e trabalhadores de saúde, oriundos de todos os estados brasileiros. A organização foi a marca do evento, que contou com aproximadamente 1.800 inscritos e submissão de mais de mil trabalhos científicos e relatos de experiências em educação médica. O programa científico contemplou fóruns e temas prioritários para a ABEM e escolas médicas, tais como o desenvolvimento do docente para as novas propostas de ensino-aprendizagem, e fóruns tratando de questões fundamentais como: atenção básica de saúde, avaliação das tendências de mudanças na formação médica e da construção dos processos avaliativos, organização dos internatos curriculares e importância da residência médica na formação profissional ${ }^{(10)}$. A medicina baseada em evidências (MBE) e a iniciação científica como práticas efetivas no ensino também foram objetos de constante discussão. Em relação à $\mathrm{MBE}$, parece patente a dificuldade de implementação desses conceitos nas diversas escolas médicas, especialmente no que diz respeito à sua aplicabilidade no cotidiano didático e assistencial. Quanto à iniciação científica, sua valorização durante o curso de graduação se mostra uma estratégia eficaz de formação de um profissional mais crítico e reflexivo.

Corroborando as atuais tendências da educação médica brasileira, as áreas temáticas com maior número de trabalhos científicos submetidos foram: "Ensino médico e SUS - interação ensino-serviço-comunidade" ( $\mathrm{n}=202$ trabalhos); "Metodologias educacionais - avaliação do processo de ensino-aprendizagem" ( $\mathrm{n}=125)$; "Projetos pedagógicos - novos currículos e estratégias educacionais inovadoras" $(\mathrm{n}=105)$ e "Cenários de práticas" $(\mathrm{n}=95)$. Esse crescimento na produção científica relacionada à educação médica no Brasil é uma realidade, com indicadores bastante fidedignos, como a grande demanda de trabalhos apresentados em todos os eventos regionais e nacionais da área e a recente aprovação da Revista Brasileira de Educação Médica na base de dados SCIELO.

Dentro desse enfoque, no tocante ao ensino da reumatologia nas escolas médicas, se a palavra-chave é "integração", podemos destacar a possibilidade de integrar 
conteúdos básicos e clínicos, o que poderia ser feito já no estudo da anatomia topográfica, priorizando o conhecimento de segmentos importantes para o entendimento fisiopatológico de doenças osteoarticulares bastante prevalentes na prática clínica, como, por exemplo, os "Reumatismos de partes Moles" e as "Algias da Coluna". A ênfase nessas e em outras afecções do sistema musculoesquelético, muito prevalentes na prática reumatológica, também pode ser uma estratégia a ser utilizada dentro do processo de formação do médico generalista sendo, para isso, necessária a extrapolação dos muros dos hospitais universitários onde predominam

\section{REFERÊNCIAS}

1. Almeida E: Medicina Hospitalar - medicina extra-hospitalar: duas medicinas? [Dissertação] Rio de Janeiro: Instituto de Medicina Social, Universidade do Estado do Rio de Janeiro; 1988.

2. Bloom SW: Structure and ideology in medical education: an analysis of resistance to change. J Health Soc Behav 29: 294306, 1988.

3. Enarson C, Burg FD: An overview of reform initiatives in medical education: 1906 through 1992. JAMA 268: 1141-3, 1992.

4. Christakis NA: The similarity and frequency of proposals to reform US medical education: constant concerns. JAMA 274: 706-11, 1995.

5. Whitcomb ME: The teaching of basic sciences in medical school. Acad Med 81: 413-4, 2006. doenças mais raras, como as doenças difusas do tecido conjuntivo. Além disso, no ensino da reumatologia dentro das novas diretrizes curriculares, valorizar o treinamento de habilidades de comunicação que favoreçam uma melhor relação médico-paciente, com incorporação de abordagens qualitativas na apreensão de significados e percepções individuais e coletivas é ponto fundamental, quando se aborda uma área onde o principal sintoma do paciente é a dor.

Declaramos a inexistência de conflitos de interesse.

6. Wood EB, Meekin SA, Fins JJ, Fleischman AR: Enhancing palliative care education in medical school curricula: implementation of the palliative education assessment tool. Acad Med 77: 285-91, 2002.

7. Emanuel EJ: Changing premed requirements and the medical curriculum. JAMA 296: 1128-31, 2006.

8. Marins JJN, Rego S, Lampert JB, Araújo JGC: Educação Médica em transformação: instrumentos para a construção de novas realidades. São Paulo, Rio de Janeiro: Hucitec, Abem; 2004.

9. Rego STA: O processo de socialização profissional na medicina. In: Machado MH (org). Profissões de saúde: uma abordagem sociológica. Rio de Janeiro: FIOCRUZ; 1995.

10. Lampert JB: Informe da Comissão Científica / $44^{\circ}$ COBEM. Boletim ABEM 33 (3-4): 3, 2006. 